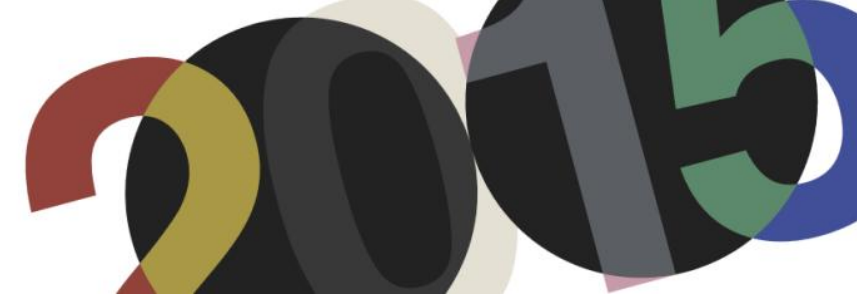

DOI: http://dx.doi.org/10.4995/LC2015.2015.586

\title{
Búsquedas para el establecimiento de una relación armónica con el paisaje. Dos exploraciones paralelas
}

\author{
C.E. Mejía Vallejo, J. Deltell Pastor \\ Escuela Técnica Superior de Arquitectura de Valencia
}

\begin{abstract}
Resumen: Los proyectos para la Sainte-Baume y para Cap Martin retoman el hilo de varias de las investigaciones realizadas previamente por Le Corbusier en torno a la vivienda de densidad media construidas a partir de muros de carga, como son las Maisons Loucheur (1929), las Maisons Murodins (1940), las Maisons pour Maîtres et Contremaîtres de la S.P.A (1940) y las Unités Transitoires (1944). No obstante, es posible afirmar que en ellos se opera una búsqueda nueva que tiene que ver con la asociación de estos módulos residenciales en pro de formar un conjunto coherente y unitario, analizando las implicaciones que ello tiene con respecto al paisaje. A la par que Le Corbusier reflexiona sobre la métrica y optimiza la distribución de estos espacios residenciales, continúa trabajando de manera intensa con la sección para intentar encontrar la manera adecuada de llegar al suelo y de relacionarse tanto con el entorno natural sobre el que el edificio se apoya, como con el paisaje lejano con el que se pretende dialogar. A esta búsqueda se suma otra que ahonda en la necesidad de una definición material acorde. A partir de estas premisas se orquesta un diálogo a varias bandas que recoge reflexiones sobre forma y proporción, sobre materialidad y sintaxis constructiva, así como sobre el entendimiento de una relación deseada entre el hombre y la naturaleza.
\end{abstract}

Abstract: The projects for the Sainte-Baume and Cap Martin take up the thread of several previous investigations by Le Corbusier about the medium density housing built from load-bearing walls, as they are the Maisons Loucheur (1929), the Maisons Murodins (1940), the Maisons pour Maîtres et Contremaîtres of the SPA (1940) and the Unites Transitoires (1944). However, one can say that in them lies a new search that has to do with the association of these residential units in favour of forming a coherent and unified whole, analysing the implications that those create with the landscape. At the same time that Le Corbusier makes a reflexion on metrics and optimize the distribution of these premises, he continues to work intensively with section in order to try to find the appropriate way to reach the ground and to relate both to the natural environment on which the building rests, as well as with the distant landscape. In parallel to this work appears a search that delves into the need for a consistent material definition according to it. From these premises he establishes a dialogue that gathers several bands reflections on form and proportion, about materiality and constructive syntax, as well as the understanding of a desired relationship between man and nature.

Palabras clave: Le Corbusier; paisaje; búsqueda; Cap Martin; Roq et Rob; Sainte-Baume. Keywords: Le Corbusier; landscape; search; Cap Martin; Roq et Rob; Sainte-Baume.

\section{Búsquedas en torno a la vivienda colectiva: 35 rue de Sèvres 1948- 1955}

En la Fondation Le Corbusier existen planos de los proyectos Roq et Rob fechados desde octubre de 1949 hasta septiembre de 1955 con algunas interrupciones. Durante este tiempo Le Corbusier fue aportando modificaciones, ensayando nuevos caminos y realizando múltiples variaciones sobre diversos temas. La extensión en el tiempo que ocupan estos proyectos no construidos y la manera discontinua cómo se trabajaron hacen suponer que para Le Corbusier se trataba probablemente de un "laboratorio" de investigaciones, antes que de una apuesta concreta por construir un edificio. De hecho el encargo fue básicamente auto promovido por el propio Le Corbusier, aunque con la complicidad con su amigo Robert Rebutato -propietario de l'Étoile de Mer y de los terrenos adyacentes en los que estaba previsto ubicar Rob- . 
En el momento en el que inicia esta nueva reflexión en Cap Martin Le Corbusier estaba llevando simultáneamente varios proyectos que recorrían caminos casi antagónicos. Entre 1944 y 1958 las reflexiones de Le Corbusier sobre la residencia gravitaron en torno a tres polos: los edificios del tipo Unité d'Habitation, las viviendas unifamiliares singulares (por lo general de planta cuadrada) y los conjuntos residenciales de densidad media. En cada uno de estos "tipos" de proyectos Le Corbusier abordaba cuestiones diferentes, independientemente de la particularidad del programa.

Al hilo de una recherche patiente, organizada y sistemática, Le Corbusier utilizaba los distintos proyectos que se le encargaban -o que él mismo promovía- para indagar cuestiones que trascendían lo inmediato que se estaba proyectando. Las búsquedas apuntaban a aspectos diversos que muchas veces no eran explorables en un mismo proyecto.

El presente artículo se centrará en dos proyectos residenciales de densidad media -Le Village de Pèlerinage de la Sainte-Baume y Roq et Rob-proyectados entre 1948 y 1956 en el 35 rue de Sèvres, ya que se entiende que será en ellos en los que Le Corbusier realice una apuesta clara por definir otra manera de relacionarse con el paisaje.

Para llevar adelante esta búsqueda se podría decir que básicamente se movilizaron cinco parámetros, que cuidadosamente se fueron recombinando:

1.1 La configuración de la planta mediante la repetición de crujías paralelas manifiestas.

1.2 La definición de la estructura -en particular en lo que atañe al encuentro con el suelo y a la transición entre éste y la parte aérea-.

1.3 La sintaxis material.

1.4 La configuración volumétrica.

1.5 Formas de relación con el paisaje.

\subsection{La configuración de la planta}

Quizás sea una simplificación excesiva aventurarse a afirmar que existe una relación entre el "tipo" de edificio a desarrollar y la configuración básica de la planta mediante la cuál éste se aborda. No obstante, durante esta época, resulta posible identificar la utilización recurrente de dos configuraciones básicas para abordar el tema de la vivienda colectiva: bloques lineales, para resolver vivienda de alta densidad y edificios compuestos a partir de crujías paralelas manifiestas, para las viviendas de densidad media. En estos últimos se apuesta claramente por una configuración lineal, en la que a pesar de constituir un único cuerpo construido no obstante se independizan visualmente las diferentes unidades.

Dichas organizaciones de la planta van acompañadas de investigaciones en torno a los sistemas de circulación tanto horizontal como vertical, a las soluciones estructurales y a los mecanismos de configuración volumétrica de los alzados.

\subsection{La definición de la estructura}

Aunque existen diversas combinaciones entre la organización de la planta y el sistema estructural propuesto, por lo general, cada configuración de la planta lleva asociado un tipo de sustentación que de alguna manera le es consustancial. 
No obstante, resulta interesante anotar que así como en los bloques lineales Le Corbusier tiene muy claro el carácter diferencial de la estructura aérea y de aquella que resuelve el contacto con el terreno (a pesar de que en cada uno de ellos se opere un búsqueda concreta), en los proyectos de crujías paralelas aparentemente existen dudas sobre cuál debe ser la forma de la estructura que opera la transición con el terreno y sobre cómo debe ser el diálogo establecido entre ésta y la parte aérea. Es por ello que, en los distintos proyectos realizados en esta época bajo estas premisas, se prueban diferentes tipos de soluciones apareciendo siempre un conflicto entre la voluntad de definir el límite entre las células mediante un elemento constructivo contundente, asimilable al muro, y el deseo de posarse sobre el territorio con el menor impacto, lo que remite a la utilización de elementos puntuales.

Le Corbusier irá alternando la utilización de los dos sistemas, llegando incluso a combinarlos en una misma solución. También está presente el deseo de independizar volumétrica y visualmente las células, que lo lleva a tantear estructuras duales que permitan el deslizamiento relativo de los cuerpos.

\subsection{La sintaxis material}

La manipulación de la percepción de los edificios y de los espacios interiores en función de su construcción incluye tanto la elección de los materiales como la forma de relacionarlos entre ellos.

Al mismo tiempo que en estos proyectos residenciales de densidad media se fuerza una lectura fragmentada de las partes que componen el volumen, también se apuesta por una forma de construcción en la que se hacen explícitos los diferentes materiales utilizados potenciando una lectura diferenciada de los mismos, en cuanto éstos vienen asociados de manera indefectible a su función portante y constructiva. Es difícil afirmarlo con certeza, al tratarse de proyectos no construidos, pero muy probablemente en ellos Le Corbusier habría de renunciar poco a poco a la utilización de la policromía optando por una expresión de las cualidades sensibles de los distintos materiales.

Esta postura tiene una doble repercusión que incide en la construcción del volumen en sí, ya que fuerza una sintaxis material entre partes diversas, y en la relación de éste con el entorno circundante. La utilización de materiales "brutos", que asume claramente su diversidad, sin duda remite a la manera como se construye el paisaje como suma e integración de factores diversos.

No obstante las investigaciones en este sentido van de la mano de las búsquedas en torno a la estructura, por lo que al igual que sucede con ésta se irán alternando soluciones diversas e incluso al parecer contradictorias.

\subsection{La configuración volumétrica}

Los elementos responsables de la configuración volumétrica, y de la consecuente imagen del alzado, también parecen ser susceptibles de ser leídos desde una cierta sistematización. Fundamentalmente, a lo largo de estos años Le Corbusier explora dos mecanismos en el desarrollo de sus proyectos residenciales: el trabajo con planos sucesivos en aras a conseguir una mayor abstracción en la lectura del volumen como un todo (Unités d' Habitation) y la expresión e individualización del entrepaño definido conjuntamente por la estructura y la forma de la cubierta (Unités Transitoires, Roq et Rob, La Citadelle, etc) -como herramienta para singularizar la lectura de las distintas unidades. 
Vemos pues cómo para un mismo programa, dependiendo del carácter que se le pretendía imprimir al volumen, se optaba por un tipo u otro de solución. Las condiciones específicas de la localización geográfica, si bien influían en la particularización de las soluciones adoptadas, no parecían ser determinantes a la hora de decidir el carácter general de los edificios. Soluciones empleadas en Francia eran susceptibles de ser llevadas a la India, o viceversa.

No obstante sorprende particularmente el trabajo simultáneo en torno a dos formas casi opuestas de manipulación de los aspectos formales y constructivos, en aras a potenciar distintas lecturas escalares y visuales: el recurso a la composición por planos sucesivos (brise soleil) y la individualización de la célula (trabajo con crujías paralelas). Parece claro que Le Corbusier utilizó estas cuestiones como un verdadero laboratorio de expresión lingüística, extrayendo de cada una de ellas soluciones y situaciones espaciales adecuadas para cada proyecto.

La utilización sistemática del brise soleil abunda en la búsqueda de una determinada abstracción en la aprehensión de los edificios. Este recurso posibilita una lectura dual del límite exterior del edificio, mediante la interposición de un espacio de aire que permite establecer una diferenciación entre el alzado que manifiesta las particularidades del uso y el alzado que se muestra al exterior, trabajando la globalidad de sus proporciones. Se trata de un trabajo mediante planos sucesivos en el que el brise soleil es el responsable de la relación con el exterior, mientras que el pan de verre hace las veces de filtro con el interior.

Aunque el brise soleil a buen seguro cumple una determinada función en el control del soleamiento, está claro que su papel excede con creces de este cometido. Se trata también de un recurso eminentemente compositivo, o si se prefiere pictórico, que junto con la proporción general del paño que organiza, constituye la pauta para la lectura del alzado. También permite a Le Corbusier conferir un espesor ficticio a la materia, potenciando así la aparición de efectos claramente vinculados al manejo plástico de la misma como son el relieve, el contraste y el claroscuro, entre otras.

Como contrapunto y necesario complemento del brise soleil aparece el pan de verre ${ }^{l}$. Del diálogo entre ambos surge la posibilidad de incorporar escalas múltiples dentro de una lectura unitaria del conjunto. El pan de verre trabaja con la escala del usuario, con un nivel de proximidad en el que le resulta posible reconocer un sistema pensado a su medida para ventilar, para mirar y para -en ciertos casos- apoyarse.

Mediante la combinación de estos dos mecanismos Le Corbusier establece una doble lectura de las fachadas del edificio: una se concibe para ser vista en su totalidad y desde el exterior, mientras que la otra lo hace para ser vista en su particularidad y desde el interior. Se trata de un sistema extremadamente especializado y refinado en su dualidad.

En los edificios en los que se emplea este mecanismo dual, la relación tanto con el suelo como con el cielo se formaliza de una manera particular, cosa por otro lado obvia atendiendo al voluntario trabajo del lienzo de

\footnotetext{
${ }^{1}$ Es importante anotar que la investigación en torno al pan de verre se extiende a los paños ligeros de fachada utilizados tanto en los proyectos que utilizan brise soleil como en los que no, especialmente en las construcciones que apuntan a un cierto grado de industrialización.
} 
fachada como una unidad en sí. En este sentido, el adoptar soluciones particulares y diferenciadas en los extremos del edificio no hace más que reforzar el carácter "terminado" de la obra, reforzando el hecho de que el lienzo principal responda de manera precisa a una determinada proporción.

Otra búsqueda bien diferente es la que Le Corbusier lleva a cabo en los proyectos en los que opta por la utilización de crujías paralelas explícitas. En ellos el sistema que se utiliza apunta hacia el deseo de promover una cierta manipulación escalar recurriendo a la fragmentación del volumen -mediante la expresión e individualización del entrepaño definido conjuntamente por la estructura y la forma de la cubierta- y de dotar a los edificios de un determinado carácter gracias a la expresión de su construcción. Si bien en el caso anterior veíamos como existía la voluntad de apostar por una lectura de la totalidad del edificio, en este caso pareciera como si el objetivo residiera en la lectura de las partes que componen la obra, bien sean viviendas independientes (por ejemplo Roq et Rob), o espacios de un interior intencionadamente pautado (Villa Manorama Sarabhai).

\subsection{La relación con el paisaje}

La diferencia entre estas dos formas de proceder anteriormente enunciadas con respecto a la definición del carácter de las fachadas difícilmente es atribuible a particularidades del programa, ya que vemos cómo edificios de vivienda colectiva se resuelven tanto con uno u otro mecanismo. No obstante, ambas establecen maneras muy distintas de relación del observador externo con el edificio, y del habitante con el exterior.

En el caso de la utilización del brise-soleil se fuerza a una lectura distante y del todo, mientras que la individualización de las células promueve un aproximación y una relación de interacción con lo construido: la contemplación contrapuesta a la experiencia.

Estas consideraciones llevan implícitas maneras diferentes de entender la relación entre lo edificado y el paisaje. En los casos en los que se recurre al brise soleil por lo general se trata de edificios que se asientan sobre el paisaje y que establecen con él un diálogo mediante la abstracción. La utilización del brise soleil da pie a la lectura del edificio como un todo, tanto por la percepción escalar que éste conlleva, como por le hecho de ser edificios que se levantan del plano del suelo. Estas dos cuestiones surgen quizás como respuesta a una necesidad de establecer un contrapunto con el paisaje, entendido como panorama.

Por el contrario cuando Le Corbusier recurre a muros de carga perpendiculares al plano de fachada como responsables últimos de la imagen del edificio, la relación con el paisaje se invierte. Los edificios pasan de colocarse sobre el paisaje a enraizarse en él. Vistos desde fuera parecen surgir del paisaje. En estos caso se apuesta por una percepción más fragmentada, potenciada por la definición material de los edificios, que establece un diálogo con los elementos que construyen el paisaje y no con la totalidad del mismo, aunque éste siempre siga estando como fondo.

En el texto de presentación de la Villa Mandrot en l' Euvre Complète se puede leer "La composition est ordonnée sur le paysage »" En este proyecto de 1929 ya aparece la voluntad de definir la forma y la materialidad de lo construido en sintonía y estrecho diálogo con el entorno que lo rodea.

La consecuencia última de las distintas formas de combinación de los factores anteriormente mencionados es el establecimiento de diferentes formas de relación entre la pieza construida y el paisaje en el que se asienta. Las

\footnotetext{
${ }^{2}$ LE CORBUSIER (1957). Euvre complète, Verlag für Architektur, Artemis, Zurich; octava edición 1991. Vol. 2. Pag. 59
} 
primeras a las que se alude son hitos en el paisaje, que se posicionan sobre él pero que no interactúan, mientras que las segundas construyen el paisaje estableciendo un diálogo próximo con los elementos que lo rodean.

A continuación se intentará realizar una aproximación a las búsquedas llevadas a cabo por Le Corbusier en este sentido entre 1948 y 1954 analizando dos ejemplos.

\section{Reflexiones en torno a dos proyectos}

Quizás el proyecto en el que Le Corbusier incide e investiga de forma más exhaustiva estas cuestiones son los conjuntos residenciales Roq et Rob, en Cap Martin. No obstante, es importante señalar que este proyecto presenta muchas similitudes con las propuestas realizadas para el Village de Pèlerinage de la Sainte-Baume, realizado en paralelo e iniciado unos años antes, por lo que se considera oportuno presentarlos a la par.

Refiriéndose al fracaso del proyecto para la Basilique de la Paix et du Pardon Le Corbusier escribió las siguientes palabras:

"Mais ceux qui cherchent à lier les choses de l'homme et les choses de la nature en une harmonie subitement valable, se font aigrement rejeter et rien ne se fait! (...) La surface de l'eau... n'est plus troublée, tout va bien; chacun dormira tranquille! (...)”.”.

"Lier les choses de l'homme et la nature en une harmonie subitement valable"; con estas palabras Le Corbusier hace explícita su voluntad de promover una armonía entre lo construido y el entorno natural. Esta vía de investigación lo ocupó a lo largo de muchos años y quizás nunca pudo llegar a ver sus frutos, pues ninguno de los proyectos en los que exploró esta cuestión de una forma más consistente llegaron a ser construidos.

\subsection{Primeras búsquedas}

En torno a estas propuestas se operan varias búsquedas que están relacionadas con la métrica de la crujía básica búsqueda de una modulación que permita optimizar las distribuciones interiores-; con la relación con el plano del suelo -resolución de la dicotomía entre la voluntad de levantar las construcciones del terreno y la utilización de un sistema estructural que llega a él de forma contundente- y con la voluntad de diferenciar y cualificar los espacios mediante una especialización de la sección -búsqueda en torno a posibles maneras de rematar los espacios y en general los volúmenes, lo que conlleva a su vez exploraciones en torno a la forma de la cubierta-.

Hay decisiones que presentan una gran estabilidad, y que a lo largo de las distintas propuestas se van perfilando como definitivas como son: el recurso a la planta desarrollada en profundidad compuesta por dos crujías paralelas -de una dimensión en torno a los 2.26 metros de ancho-; la voluntad de manifestar de forma explícita cada unidad mediante su expresión y la singularización de la cubierta; la contigüidad de los módulos en planta, mas no necesariamente en alzado - mediante la alteración tanto de la línea de cornisa como de la del remate inferior- y la voluntad de independizar el espacio habitable con respecto a la cota del terreno. También al parecer alberga pocas dudas con respecto al tipo de cubierta a utilizar ya que siempre la define construida con bóvedas. Incluso en las soluciones ligeras utiliza esta solución constructiva, haciendo la siguiente descripción de la

\footnotetext{
${ }^{3}$ PETIT, J.(1970). Le Corbusier Lui-même. Éditions Rousseau, Genève.
} 
misma: "l'une des premières recherches conçues en tôle d'aluminium pliée, la toiture voûtée étant recouverte de béton, de terre et de plantes grasses"

Recorriendo la información de estos dos proyectos, queda patente la continuidad pero al mismo tiempo la diversidad de la búsqueda. Ésta se hace explícita por ejemplo cuando se constata que en Octubre de 1949 en el 35 Rue de Sèvres, se estaba dibujando la propuesta para la Trouinade construida con muros de tapial y en diciembre de ese mismo año también se avanzaba con la propuesta de Rob, formalizada con el sistema $226 * 226 * 226$ de alveolos de aluminio.

En relación a esto, Le Corbusier escribió en las páginas de su Euvre Complète dedicadas al proyecto de Roq et Rob :

“Les études se sont poursuivies, basées tantôt sur une technicité, tantôt sur une autre, à la recherche d'une type d'habitation et d'exploitation de l'habitation sur les rives de la Côte d'Azur, capable de s'insérer dans le paysage et propre à le vitaliser. "5

Estos dos proyectos estarán marcados por las búsquedas dispares tanto en torno a la estructura como a la materialidad. No obstante, atendiendo a las palabras de Le Corbusier, es posible intuir que el sentido de éstas trascendía su estricto cometido. Se parte de la hipótesis de que es posible afirmar que tanto en la Sainte-Baume como en Roq et Rob, la búsqueda en torno a la asociación de módulos residenciales -en pro de formar un conjunto coherente y unitario- apunta hacia la voluntad de promover una determinada forma de relación con el paisaje.

Hasta ahora las búsquedas de Le Corbusier relacionadas con la construcción en terrenos naturales se habían centrado en construcciones aisladas, o en todo caso en conjuntos compuestos por construcciones independientes, por lo que resulta posible lanzar la hipótesis de que se trata de las primeras aproximaciones del maestro suizo a este tema. De hecho sus propias palabras consignadas en la reseña del proyecto para la Sainte-Baume en la obra completa nos dan cuenta de ello:

"Tout était déférence au paysage, modulé sur le paysage, expression même du paysage: paysage vue des bâtiments, ou paysage fait de la présence des bâtiments dans une harmonie passionnément désirée." 6

El hecho de enfrentarse a la definición de un conjunto a buen seguro le permitió precisar cuestiones sobre las que antes se dudaba, como por ejemplo el recurso a la bóveda. En algunos croquis para las Maisons Loucheur (1929) (FLC 18354) se puede observar ya la tentación a cubrir con bóvedas los espacios. Estos tanteos tímidos se repiten en la viviendas para la S.P.A en Lannemezan ${ }^{7}$. No obstante, tanto en Roq et Rob como en la SainteBaume esta solución constructiva para la cubierta se asume claramente desde el inicio, ya que le permite fragmentar las distintas partes del conjunto -controlando la escala-, y al mismo tiempo dotar de una imagen homogénea al conjunto mediante su repetición.

\footnotetext{
${ }^{4}$ LE CORBUSIER (1953). CEuvre Complète, Verlag für Arkitektur (Artemis), Zürich,Vol. 5, pag 60

${ }^{5}$ LE CORBUSIER (1953). Euvre Complète, Verlag für Arkitektur (Artemis), Zürich,Vol. 5, pag 60

${ }^{6}$ Ibidem, pag. 25

${ }^{7}$ Una vez más surge la duda sobre si hay errores de catalogación ya que en los DVD plan Vol. 3 y Vol. 7 hay dibujos idénticos en los apartados de las Maisons Loucheur y las viviendas para el complejo SPA.
} 
Las propuestas de 1949 para la Trouinade ${ }^{8}$, dibujadas por Clémot, emplean un módulo base compuesto por dos crujías paralelas de $2.26 \mathrm{~m}$ de ancho y 22.6 metros de longitud, delimitadas por muros de tapial de 0.55 metros de espesor.

Esta métrica retoma, optimizándola, la utilizada en las Maisons Murondins (1940), que parte de dos crujías de 3 metros y tres muros de 0.50 de espesor. La longitud propuesta para estas construcciones es de 40.5 metros, pero dado que por lo general cada construcción está compuesta por dos zonas, cada una de ellas tiene aproximadamente 20 metros. Las Maisons Murondins están pensadas, no obstante -y al contrario que las propuestas para la Trouinade- como un espacio dependiente de su lado largo para abrirse al exterior, actuando como principal responsable de la visión de las mismas. La dimensión de las crujías que las definen surge aunando una dimensión útil para disponer una cama en perpendicular y un paso y una dimensión suficientemente pequeña susceptible de ser cubierta con rondins de madera transportables manualmente.

Aunque las Maisons Murondins surgieron de la necesidad de dar respuesta a una situación de precariedad debida a la guerra, y desde esta óptica se entienden las pautas de su concepción, desde hace varios años Le Corbusier venía haciendo esfuerzos por intentar conciliar lo más avanzado de la industria de su tiempo con un saber hacer y una cultura material ancestrales. Las Maisons Loucheur (1929) son un claro ejemplo de esto y, como continuación de la reflexión de aquellas, el proyecto en Lannemezan (1940) también lo es.

A la par que Le Corbusier reflexiona sobre la métrica y optimiza la distribución de los espacios residenciales, continúa trabajando de manera intensa con la sección para intentar encontrar la manera adecuada de llegar al suelo y de relacionarse tanto con el entorno natural sobre el que el edificio se apoya como con el paisaje lejano con el que se pretende dialogar. En un primer momento, tanto en este proyecto como en los tanteos para Roq et Rob, se asume como premisa básica que las construcciones deben estar levantadas del suelo para favorecer ese diálogo. Esto quizás sea una herencia directa de las Unités d'Habitation, en las que unos de los puntos clave era el tener una mínima ocupación del suelo con una máxima cantidad de viviendas, permitiendo que el terreno libre pasara por debajo de ellas. Sin embargo, en estas pequeñas construcciones el problema es otro y la relación con el paisaje se deberá plantear en términos mas sutiles. Es por eso que veremos cómo a lo largo de la evolución de estos dos proyectos Le Corbusier va realizando tanteos múltiples al respecto.

\subsection{Le Village de Pèlerinage de la Sainte-Baume (1948-1954)}

El proyecto para la Sainte-Baume comparte con Roq et Rob su carácter altruista. En este caso el encargo es promovido por Édouard Trouin, geómetra y propietario de una gran extensión de terrenos en la Sainte-Baume, hermoso paraje montañoso en torno al Plan d'Aups, con el Mont Sainte Victoire como tela de fondo hacia norte. Se dice que en estas montañas, en una gruta a media altura, habitó María Magdalena. Trouin, un apasionado emprendedor, amante de la naturaleza y de lo bello, no quería parcelar sus tierras y borrar así las huellas de un entorno natural privilegiado. Es por esto que se empeñó en la búsqueda de una arquitectura capaz de dialogar con este lugar sin alterarlo, proponiendo construir una basílica dedicada a María Magdalena cuyo proyecto encargó a Le Corbusier.

\footnotetext{
${ }^{8}$ La Trouinade, derivado de Trouin el promotor del proyecto, es otro nombre con el que se conocía el proyecto residencial proyectado en la Sainte-Baume.
} 


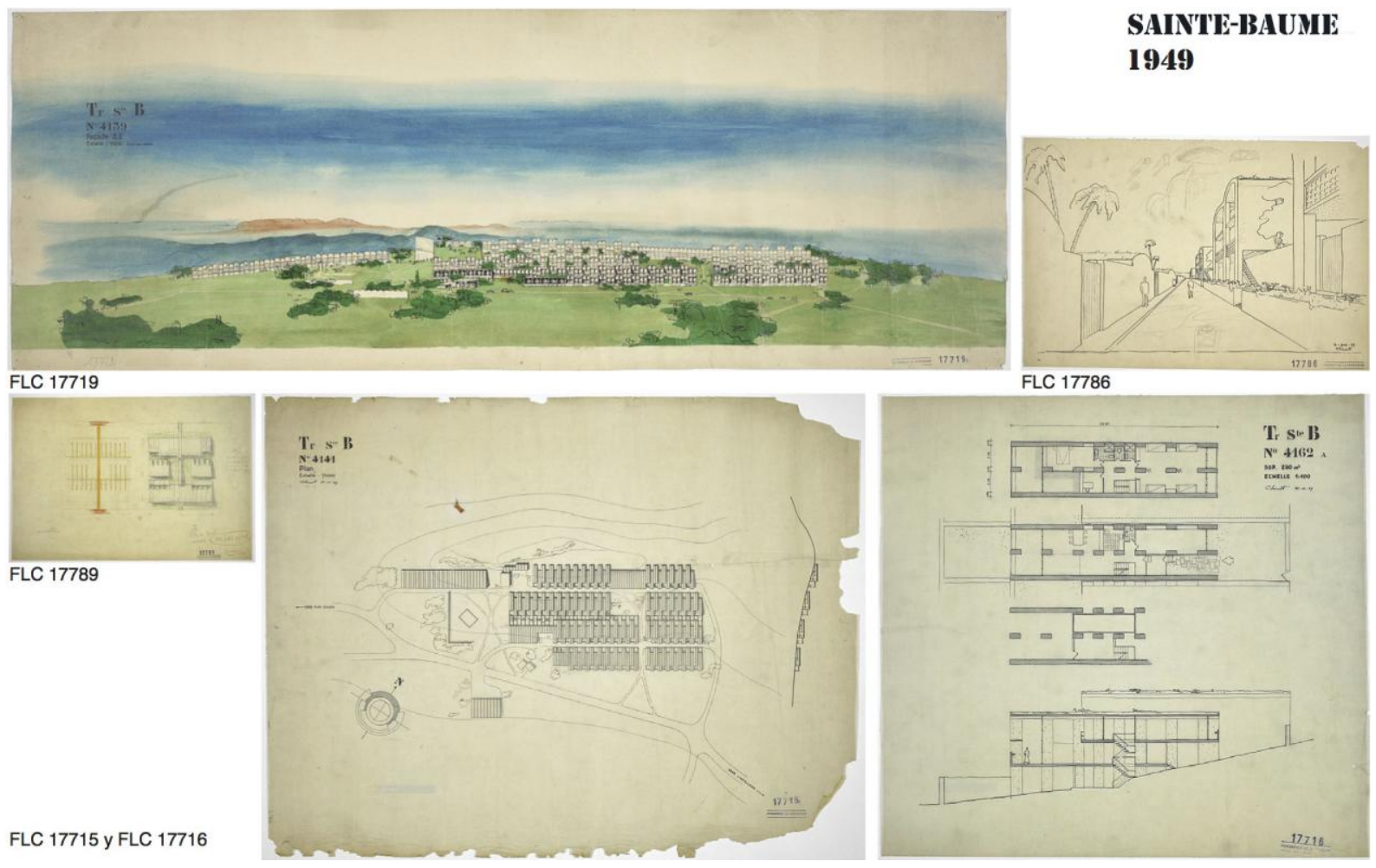

FLC 17719B (NN, NF), FLC 17786 (Clémot, 02-06-1949), FLC 17789 (Samper, 16-11-1949), FLC 17715A (Clémot, 21-101949), FLC 17716 (Clémot, 30-10-1949). Imágenes @FLC-ADAGP.

Junto al proyecto de la Basilique de la Paix et du Pardon (1946-1948) se planteó construir un Village de Pèlerinage en nombre de la paz internacional, que en principio encargó a Perret, quien no pasó de unos esquemas iniciales. Posteriormente, con la aquiescencia de Perret -quien se encontraba inmerso en los trabajos de Le Havre y Amiens- se encargó a Le Corbusier la realización paralela de esta parte del proyecto. Según parece el encargo complementario a la basílica pasó por fases muy diversas, lo que quizás explique la dispersión y diferencia de bocetos.

Los proyectos residenciales para la Sainte-Baume (1948-1954) y algunas de las propuestas para Cap Martin (1949-1956) son coincidentes en el tiempo, compartiendo varias premisas básicas como la de resolver un conjunto residencial de densidad media en un entorno natural con una impactante presencia y en desnivel. Esta coincidencia hace que muchas de las soluciones se planteen de manera casi indistinta, a tal punto que en la clasificación realizada en los DVD Plans hay varios dibujos catalogados de forma indiscriminada en ambos proyectos: dibujos de la Sainte-Baume aparecen en el proyecto de Roq et Rob y viceversa.

En ambos casos se retoma el hilo de varias de las investigaciones realizadas previamente en torno a la vivienda de densidad media construidas a partir de muros de carga como son las Maisons Loucheur (1929), las Maisons Murondins (1940), las Maisons pour Maîtres et Contremaîtres de la S.P.A (1940) y las Unités Transitoires (1944).

En las primeros dibujos para la Trouinade la totalidad del espacio se levanta del suelo debido, según Le Corbusier, debido al desnivel presente en el terreno. No obstante sorprende ver cómo este espacio de aire ni se representa ni se vive como parte de la vivienda. De hecho, en el dibujo en perspectiva seccionada (FLC 17726) se muestra el espacio cortado a nivel de la primera planta interior. 

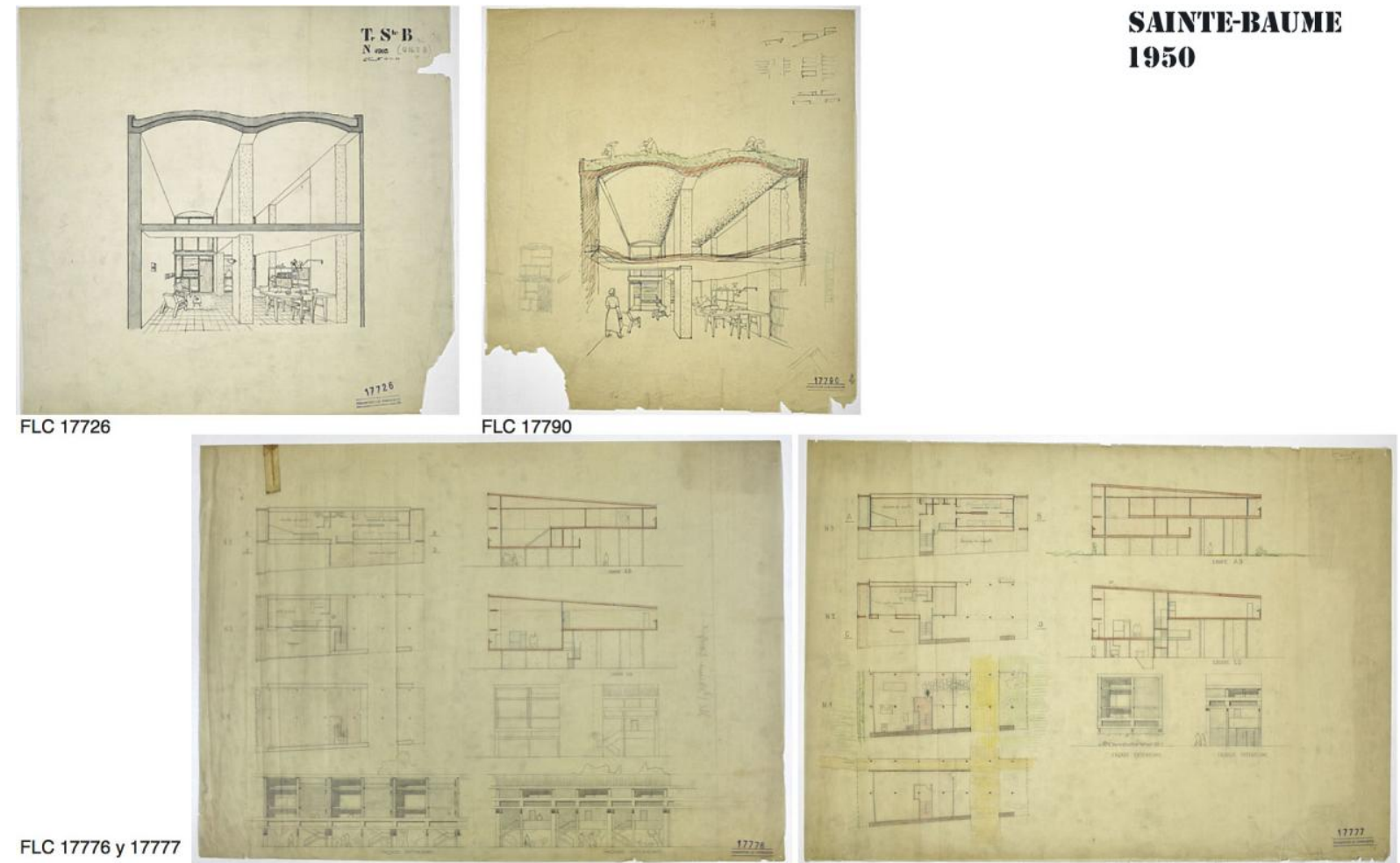

FLC 17726 (Clémot, 19-05-1950), FLC 17790 (Le Corbusier, NF), FLC 17776 (NN, NF), FLC 17777 (Clémot, 19-04-1950). Imágenes $\odot$ FLC-ADAGP.

En la propuesta que data de 1951 sorprende ver cómo se reduce drásticamente el número de viviendas proyectadas, aunque parece claro que se trata de una primera fase de un desarrollo futuro. A pesar de que el esquema resulta análogo al inicial, las particularidades del mismo difieren. Se sigue manejando un esquema de dos crujías paralelas, con la salvedad de que en este caso la línea intermedia de carga está definida por soportes, aparentemente metálicos. La dimensión total de la vivienda se reduce, pasando a dos crujías de 2.26 metros aproximadamente ${ }^{9}$ de ancho por 10 metros de longitud y dos plantas.

Parece que toda la construcción se levanta del suelo al igual que en la propuesta anterior, pero se introduce un cambio sustancial. Tanto en el espacio de acceso a las viviendas como en el ámbito con el que éstas se vinculan con el paisaje se incorporan unos espacios previos, acotados por muros curvos. Si bien en la planta no se obtiene demasiada información sobre estos espacios exteriores, en la sección se puede apreciar la aparición de un árbol dentro de cada uno de ellos y la presencia de un hilo de humo dirigiéndose hacia el cielo, lo que habla probablemente de una vida intensa en el exterior (FLC 17331). Esta operación, aparentemente anodina, supone un cambio conceptual importante. Se pasa de la sección que omite dibujar la planta baja a la creación de un espacio interior al exterior, en el que la mujer y el hombre resguardados a la sombra del edificio (FLC 17730) prolongan el espacio de la vida doméstica disfrutando de su árbol. Con respecto a la relación inversa, lo que se ve desde el paisaje, también se opera una modificación importante: no se confía en la visión de un elemento que se levanta del suelo sino que se busca reproducir las formas de la naturaleza construyendo un paño mineral ondulante que emerge directamente del suelo, como las montañas.

\footnotetext{
${ }^{9}$ No existen cotas en los planos que permiten conocer con precisión sus medidas
} 

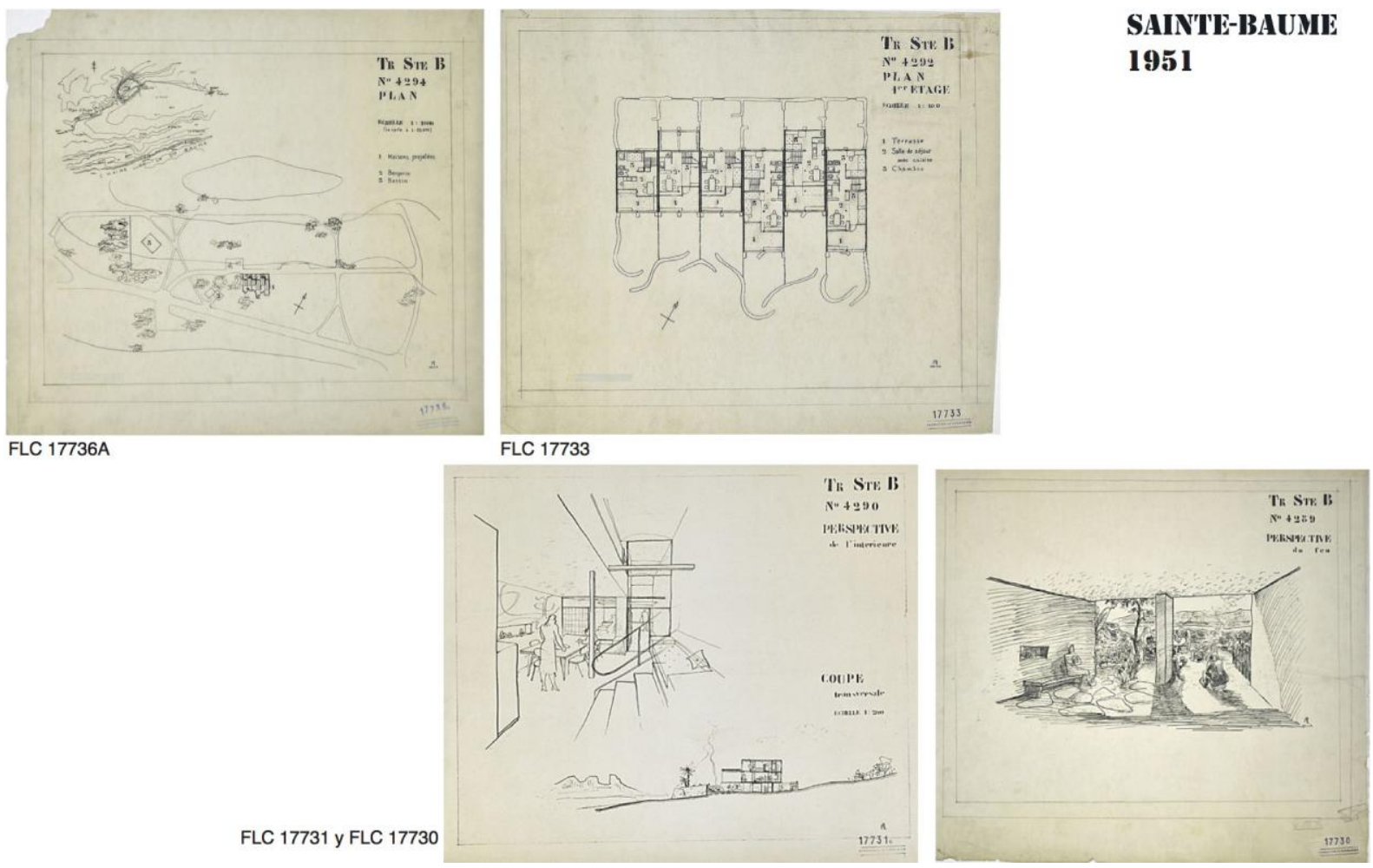

FLC 17736A (Takamasa, 23-02-1951), FLC 17733A (Takamasa, 23-02-1951), FLC 17731B (Takamasa, NF), FLC 17730 (NN, 19-02-1951). Imágenes @FLC-ADAGP

En paralelo a estos tanteos, en 1950 se empieza a gestar otra propuesta que difiere sustancialmente de las anteriores. Responde al esquema de la "barca" con formas de reminiscencias religiosas (FLC 17776, FLC 17777, FLC 17737, FLC 17738, FLC 17794A, FLC 17742, FLC 17781). Durante el proceso de concreción esta forma aparecieron también edificios o conjuntos circulares, que atendiendo a la carta de Trouin archivada en la Fondation Le Corbusier (FLC 17751) pueden responder a una imposición por parte del cliente. No obstante, en los Carnets (D16, fig. 171) figura un boceto de 1950 que muestra la plaza de toros de La Santamaría en Bogotá, en el que se puede leer la siguiente anotación: "La Plaza del Toro// confirmation des anneaux de 200 de la Ste Baume”. En el mismo Carnet figuran mas bocetos de dicho edificio en los que se incide en su diálogo con el paisaje.

En el volumen 5 de l'CEuvre Complète se dice que estaba prevista la construcción de dos tipos de edificios: uno para residencia temporal y otro para residencia permanente. Quizás la diferencia entre las distintas fases del proyecto responda al hecho de que se trate de un tipo de edificio u otro -aunque esto no aparece reflejado en los planos de forma explícita-.

Esta propuesta extraña, al parecer persigue la antítesis de lo que se pretendía en los inicios del proyecto, a saber: la fragmentación de la escala. En este caso se trataba de construir un volumen unitario y con una condición de forma predeterminada y muy condicionante, en la que se hacían esfuerzos sobredimensionados por matizar su impacto. Por su carácter contundente y formalmente autónomo recuerda más las estrategias de relación con el paisaje operada en las Unités d'Habitation que la aproximación que estaba proponiendo para estos conjuntos residenciales. 

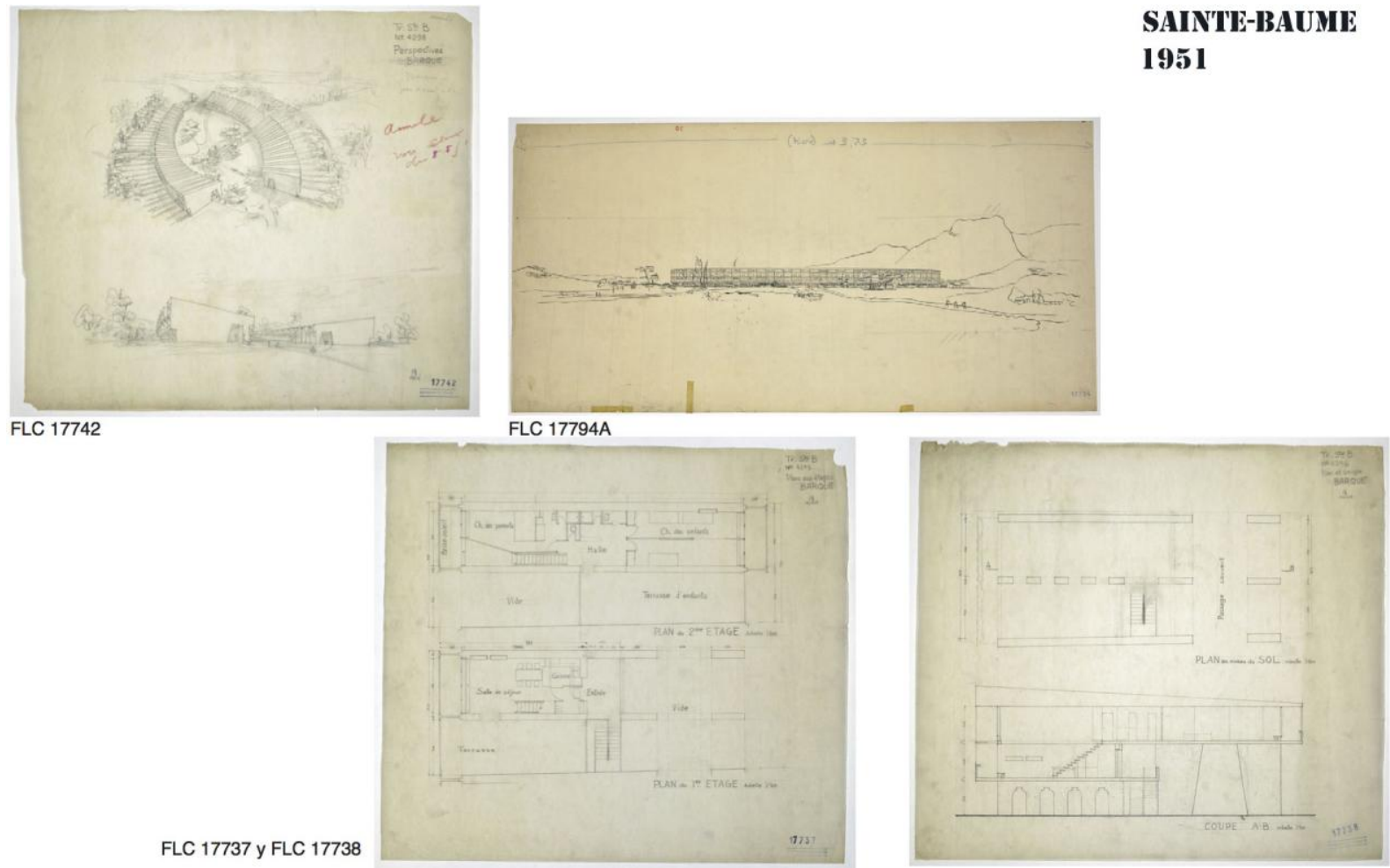

FLC 17742 (Takamasa, 01-03-1951), FLC 17794A (NF, NN), FLC 17737 (Takamasa, 28-02-1951), FLC 17738 (Takamasa, 28-02-1951). Imágenes @FLC-ADAGP.

También cabe resaltar que quizás estos tanteos pudieron coincidir también con la colaboración establecida con "l'Aluminium Français":

"Mais les circonstances avaient permis d'autres rencontres ce fut "l'Aluminium Français” qui, a un moment donné, tendit l'oreille à nos propositions; et des formes d'urbanisme et d'architecture en furent l'effet, conçues en plein voisinage possible et admissible avec le pissé, mais réalisables avec les méthodes les plus aigües d'emploi du métal le plus moderne qui est: l'aluminium",10

En las carpetas relacionadas con este proyecto aparece una serie de planos sin fechar, dibujados por Germán Samper, que coinciden literalmente con dibujos realizados para Roq et Rob en 1949 y en los que se prescinde de los muros asumiendo por completo la presencia de una estructura ligera. Es posible que éstos hayan servido de base para desarrollar los tipos que daban forma a las primeras propuestas para la Barque (F, 17777 y FLC 17776).

\subsection{Roq et Rob. Cap Martin (1949-1955)}

El proyecto de Rob estaba pensado inicialmente como el conjunto de seis residencias vacacionales para artistas y doce alojamientos para viajeros de paso. Roq era una desarrollo urbanístico más ambicioso que contaba con entre 30 y 80 viviendas según las diferentes versiones. No obstante, y sobre todo en los momentos iniciales, la investigación tipológica con respecto a la célula que definía el tipo de vivienda y sus pautas de construcción fue común (entre ellos y con la Sainte-Baume).

${ }^{10}$ LE CORBUSIER (1953). CEuvre Complète, Verlag für Arkitektur (Artemis), Zürich. Vol. 5 pag. 25. 


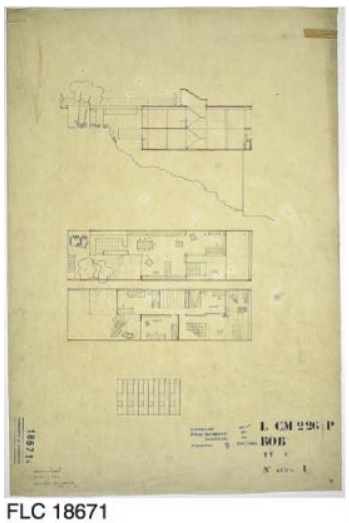

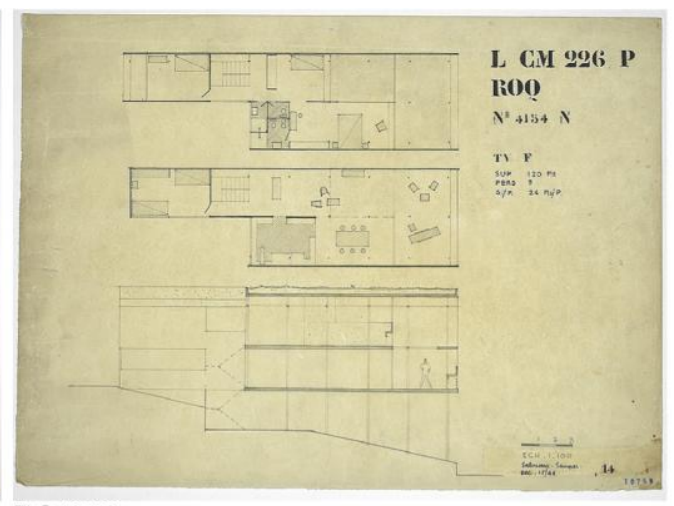

FLC 18759

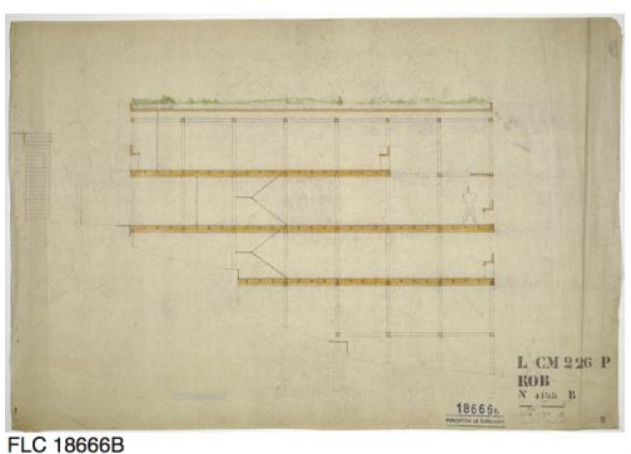

FLC 18666B

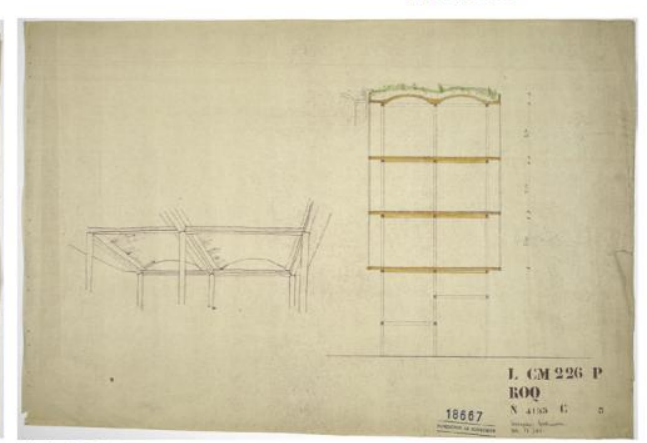

FLC 18667
ROQ ET ROB

1949
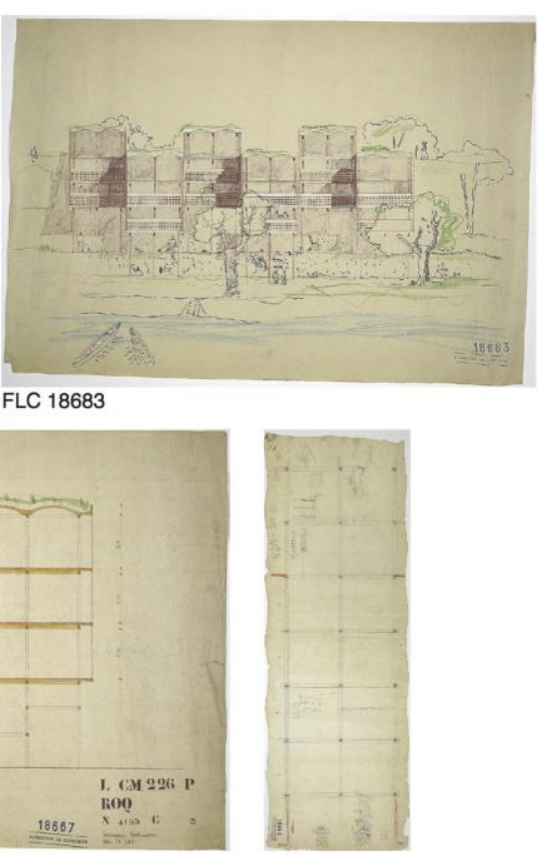

FLC 18948

FLC 18671 (Samper-Salmona, 12-1949), FLC 18759 (Samper-Salmona, 15-12-1949), FLC 18683 (NN, NF), FLC 1866B (Samper, 12-1949), FLC 18667 (Samper-Salmona, 12-1949), FLC 18948 (NN, NF). Imágenes @FLC-ADAGP.

La propuesta para Rob de diciembre de 1949, dibujada por Germán Samper y Rogelio Salmona y cuyos dibujos quizás son los que más han trascendido, exploraba el camino del 226*226*226 de una manera aparentemente muy convincente. Sin embrago vista con detenimiento es una solución que duplica la estructura, ya que la bóveda es un elemento estructural en sí independiente de la retícula de aluminio. El hecho de independizar los soportes verticales de los cerramientos de medianería da lugar a rematar las bóvedas de una forma más armoniosa, estableciendo un doble orden sutil que permite la lectura de cada crujía individualmente, pero que también da cuenta del conjunto dual que constituye la unidad residencial básica. Así mismo, en el encuentro con el suelo conduce a una solución ligera, posibilitando que los módulos de vivienda avancen o se retranqueen con respecto al contiguo con bastante independencia (FLC 18948, FLC 18666B, FLC 18667, FLC 18671A).

En tanteos posteriores dibujados por Yoshizaka Takamasa ${ }^{11}$ entre 1950 y 1951, se observan dos cambios fundamentales. El primero es que las viviendas se reducen claramente en dimensión, pasando a tener 2, 3, 4 ó 5 módulos de 2.26 metros de profundidad en lugar de los 7 que tenían las propuestas anteriores. Este cambio responde a la voluntad de ofrecer la mayor diversidad posible de viviendas, vinculada al número de habitantes que puedan ocuparlas -que oscila desde 2 hasta 2+9+1-. (FLC 18745, FLC 18754). No obstante, estos tanteos parecen haber sido desarrollados fundamentalmente en planta, partiendo de una sección esquemática que ordena los distintos tipos de forma escalonada ajustándose hacia la pendiente y organizando las viviendas de mayor a menor superficie (FLC, 18754). La imagen en alzado, de la cual aparentemente no hay dibujos definitivos, debe

\footnotetext{
${ }^{11}$ Aunque mucho de los dibujos no están firmados, ni tienen fecha, por similitud con otros se intuye que la autoría y las fechas son similares.
} 

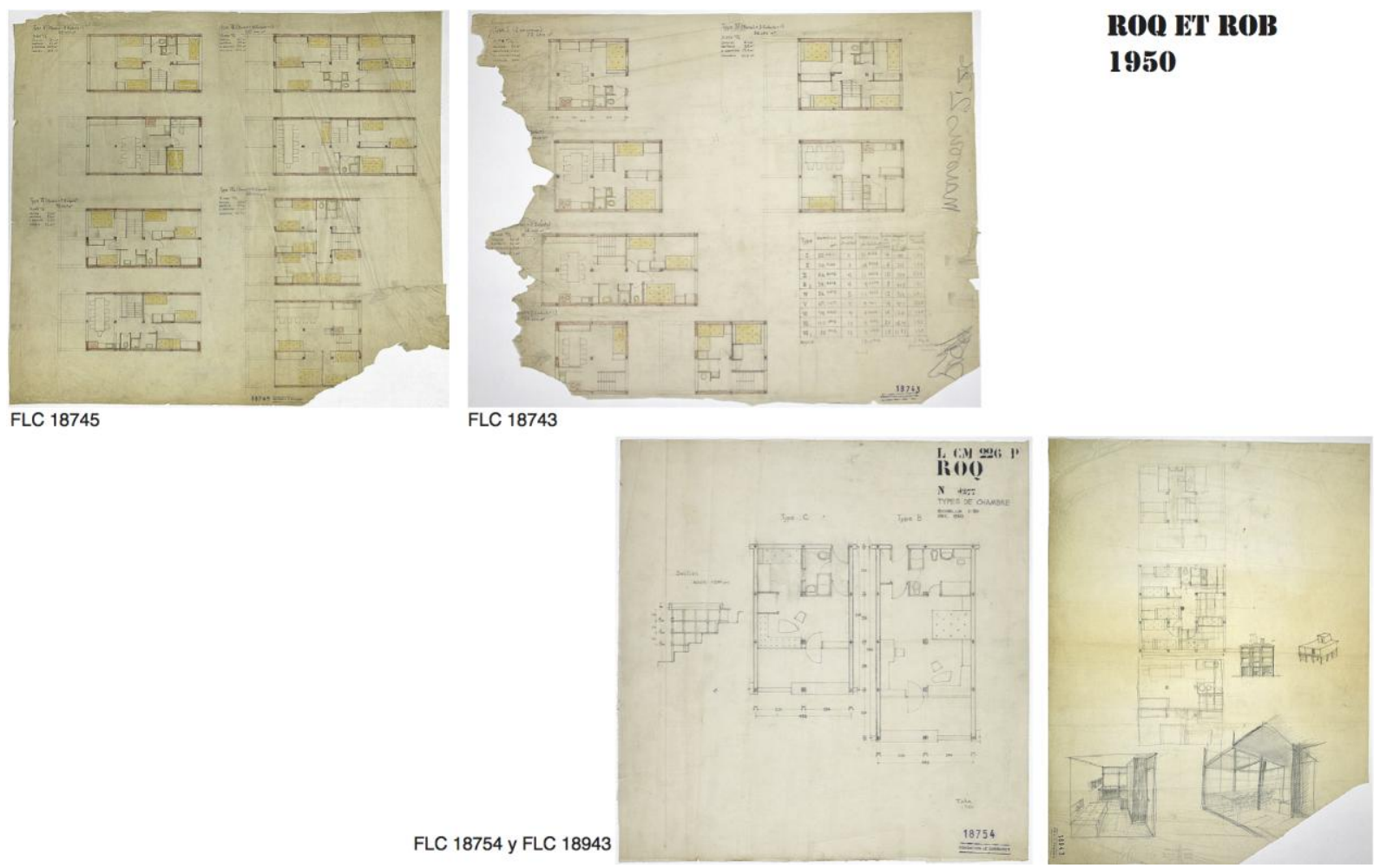

FLC 18745 (NN, NF), FLC 18743 (NN, NF), FLC 18754 (Takamasa, 12-1950), FLC 18943 (NN, NF). Imágenes OFLCADAGP.

asumir cuatro plantas y un frente continuo, lo que genera una escala excesiva para lo que se pretendía. Un tímido croquis quizás da cuenta de ello (FLC 18943).

En estos tanteos desaparece la franja de 53 (o $43 \mathrm{~cm}$ ) que delimitaba el espacio residencial a ambos lados de las dos crujías y que permitía que la bóveda se rematara de forma armoniosa. El módulo de 2.26 metros sigue rigiendo toda la composición y la decisión de duplicar la estructura en la medianera -fruto de la construcción con los alveolos de $2.26 * 2.26 * 2.26$ - parecen ser datos de partida por ahora asumidos.

Takamasa continúa con la búsqueda, planteando en febrero de 1951 otra solución que coincide parcialmente con algunas de las búsquedas para la Sainte-Baume (FLC 18740, FLC 18728). En este caso ya no se trata sólo de un estudio tipológico sino de una propuesta completa. No obstante, la sección induce a pensar que se trata de una solución inicialmente concebida para el territorio de la Sainte-Baume, cuyo desnivel es mucho menos pronunciado que el de Cap Martin. Esta vía exploraba la posibilidad de realizar un cambio entre la estructura que llega al suelo y la de la parte aérea, utilizando muros pesados en la primera y una estructura alveolar de aluminio en la parte superior (FLC 18705, FLC 18706, FLC 18770). En esta propuesta, la llegada al suelo se realiza construyendo con muros sólo los elementos portantes de los extremos, sustituyéndose la línea de carga intermedia por soportes de hormigón. Esta operación, sin duda destinada a liberar la planta baja y hacer menos pesada la imagen de la llegada del edificio al suelo, presenta no obstante ciertas incoherencias. No parece clara la literalidad de mantener las tres líneas de carga, ni tampoco la sustitución de uno de los ejes de encuentro con el suelo por soportes. La decisión de trabajar con muros, además de eventualmente resolver un problema de esbeltez de la estructura de aluminio en las plantas bajas, también a buen seguro partía de una idea de cómo realizar el diálogo con el elemento natural de apoyo. 


\section{ROQ ET ROB}
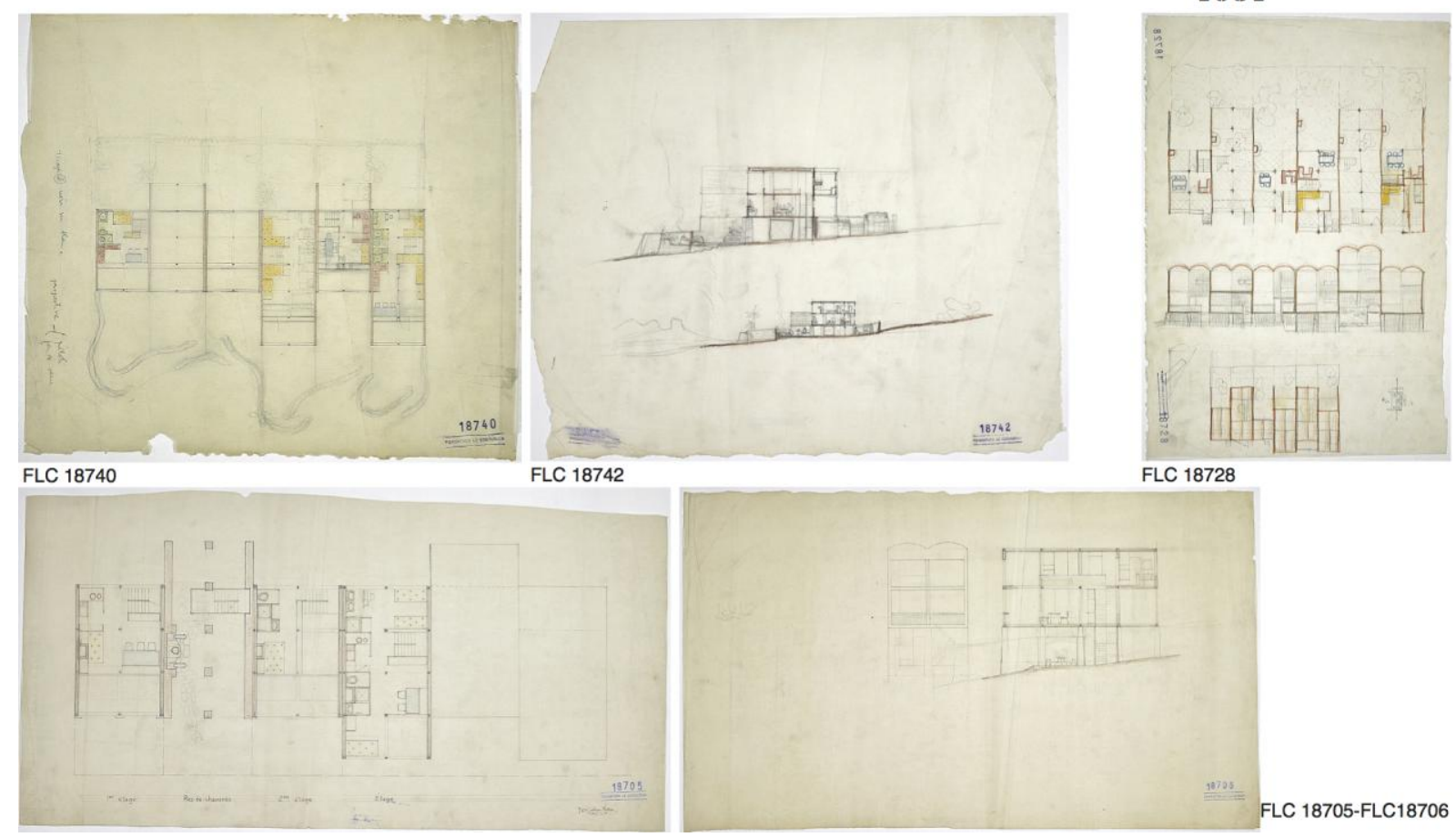

FLC 18740 (NN, NF), FLC 18742 (NN, NF), FLC 18728 (NN, NF), FLC 18705 (Takamasa, 07-07-1951), FLC 18706 (NN,NF). Imágenes @FLC-ADAGP.

A partir de aquí Le Corbusier ensaya otras maneras de resolver esta cuestión. En el dibujo FLC 18704 se pueden observar dos tanteos diferentes, ya adaptados a la topografía de la Costa Azul. En ambos casos se apuesta por una estrategia similar, modificando los tipos de estructura en cada nivel. El segundo dibujo podría coincidir con lo anteriormente visto, en donde perdía importancia la decisión de homogeneizar la altura de la línea inferior del forjado para todas las unidades. Sin embargo aquí, al aumentar la altura del espacio vacío con el fin de adaptarse a la topografía, la solución queda claramente desproporcionada. El primer dibujo apuesta por la creación de una especie de sol artificiel, similar -guardando las distancias- al utilizado en las Unités d' Habitation. En este caso sólo existe estructura vertical en la línea que coincide con el vano intermedio de estructura y la imagen del conjunto, además de resultar relativamente inestable, adquiere una contundencia ajena al planteamiento inicial. En ambas propuestas se unifica la línea inferior de la construcción y, aunque se hacen tanteos modificando la línea de cornisa, el impacto sobre el territorio parece mayor. Finalmente, estas propuestas de unificación del plano de forjado inferior conllevan otra cuestión y es que difícilmente permiten los retranqueos de piezas en planta -otra de las estrategias utilizadas para mitigar la escala del conjunto-.

Como podemos observar la cuestión no es sencilla. Tras esos dibujos tan seductores de Germán Samper y Rogelio Salmona -que no contemplaban de forma concreta las premisas de la construcción- resulta difícil encontrar una opción posible y satisfactoria.

En octubre de 1951 Aphonso realiza otra tentativa, aparentemente cambiando la cota de implantación de la propuesta con el fin de disminuir la altura de la planta baja (FLC 18929) y reduciendo el número de unidades a cinco en lugar de las seis que se habían manejado siempre hasta este momento. En él se muestran de nuevo dos cambios sustanciales: 


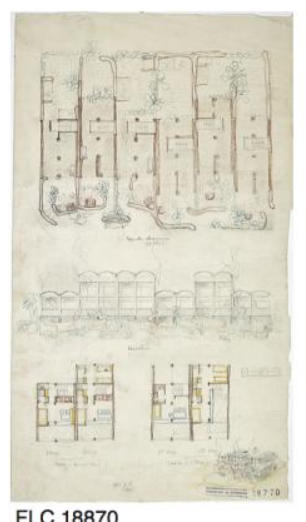

FLC 18870

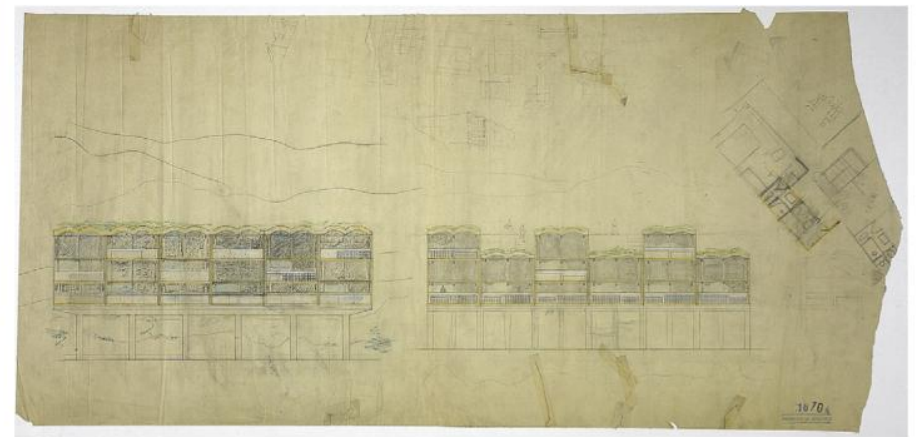

FLC 18704

\section{ROQ ET ROB}

1951

\section{FLC 18909 y FLC 18908}
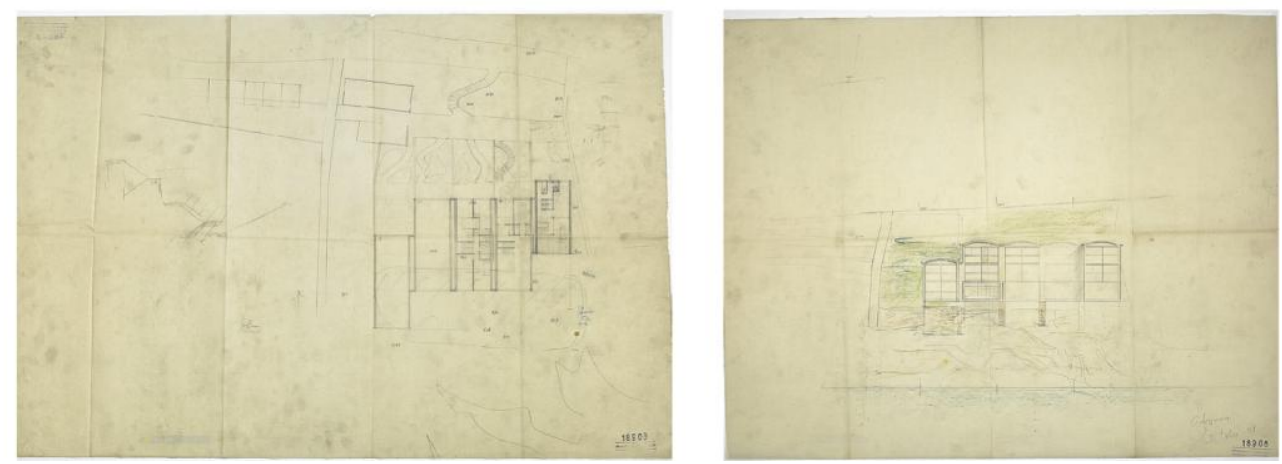

FLC 18770 (Takamasa, 08-02-1951), FLC 18704 (NN, NF), FLC 18909 (NN, NF), FLC 18908 (Aphonso, 10-1951). Imágenes @FLC-ADAGP.

el primero tiene que ver con la construcción y el carácter de la zona aérea y el segundo tiene que ver con la forma de apoyar en el suelo (FLC 18908, FLC 18909).

Por lo que se puede intuir tanto en la planta como en el alzado, en esta fase del proyecto se hace una apuesta contundente por diferenciar de forma clara, mediante sus materialidad y su construcción, el carácter de las dos partes del edificio. El encuentro con el suelo se realiza mediante muros de piedra natural de gran espesor, llegando incluso a cegar la planta baja en el primer vano a la izquierda -el más próximo al acceso- y ofreciendo la visión frontal del muro.

Con el cambio de la cota de apoyo la proporción de la planta baja se reduce, quedando así mucho más proporcionado el conjunto, aunque esto no justifique el cambio de material. Sin embargo, estudiando el dibujo del alzado con una cierta atención, se puede observar cómo la decisión de cegar frontalmente el primer vano puede partir de un deseo de diálogo y continuidad con los muros de contención necesarios para construir el "aterrazamiento", fortaleciendo de esta manera la relación con el entorno natural mediante el material.

El hecho de reducir el conjunto a cinco unidades y de modificar sus desplazamientos relativos también contribuye a logar una mayor armonía con el entorno. En la propuesta dibujada por Aphonso los tres módulos centrales permanece estables, desplazándose sólo aquellos situados en los extremos. De esta forma la percepción del conjunto, cuando se llega por cualquier de los dos laterales, es la de los muros, acotando así un espacio protegido por éstos en la zona frontal de las viviendas. 
Por el contario, la parte superior de la edificación parece asumir con mayor contundencia su carácter de construcción industrializada. Si bien en todas las anteriores aproximaciones a la definición del conjunto el aspecto del mismo parecía obedecer a una cierta voluntad de identificación con las construcciones vernáculas, en este planteamiento se asume con total radicalidad las claves de una construcción ligera: se retoma el espacio entre los módulos, que sin duda permite su ensamblaje y sirve de ajuste métrico entre la dimensión de la piedra y la de los elementos de aluminio, y se modifica incluso el espesor de la cubierta por primera vez y su construcción, planteándose a partir de una plancha curvada recubierta por tierra natural.

\subsection{Les Unités de Vacances. Cap Martin (1952-1954)}

A partir de 1952 se opera un cambio radical en la manera de abordar el proyecto de Rob que al parecer termina convirtiéndose en las Unités de Vacances para las cuales aparentemente se llegó a formalizar un proyecto entre los años 1952, 1953 y 1954. Vale la pena anotar aquí que, si bien parece cierto que el trabajo concreto sobre esta propuesta se llevó a cabo en el 35 Rue de Sèvres a partir de 1952, algunos bocetos de Le Corbusier de que datan de diciembre de 1949 (FLC 19019 P, M, Q, D, E) dan cuenta de que ya entonces el maestro lo tenía en la cabeza. En un documento fechado 4 de julio de 1952 (FLC 18924) quizás se encuentre la clave para este particular ${ }^{12}$. En él Le Corbusier intenta establecer las pautas para la gestión de una copropiedad con Rebutato en relación a los terrenos próximos a L’Étoile de Mer. Según se puede descifrar, Le Corbusier plantea que a cambio de los terrenos aledaños al Cabanon y de la posibilidad de ocupar los terrenos por debajo de éste para implantar las Unités de Vacances, Rebutato podría obtener tanto un edificio para las Unités de Camping y su explotación, como la propiedad de las Unités de Vacances, aunque el uso esté reservado a Le Corbusier y sus colaboradores.

El proyecto está concebido como un lugar de trabajo y el coste de construcción de Las Unités de Vacances correría a cargo de Le Corbusier. Es posible que Le Corbusier decidiera cambiar de estrategia al ver que el proyecto de Roq -de mayor envergadura y que por lo tanto sin duda lograría optimizar los costes de una construcción industrializada- no tenía opciones de salir adelante, ya que de hecho en los últimos años sólo se veían propuestas directamente vinculadas a Rob-. El cambio apunta hacia una simplificación de la construcción y una minimización del espacio, aprovechando la experiencia del Cabanon del cual toma posesión en agosto de 1952. Quizás la necesidad de auto financiar el proyecto lo lleve a se más pragmático, proyectando estrictamente en base a sus necesidades y a una construcción que conoce y domina, con la colaboración fructífera de Barberis en Córcega.

Tras la intensa búsqueda realizada en torno a las viviendas compuestas por dos crujías paralelas, ordenadas mediante el módulo 2,26 y con espacio abovedado, sorprende la solución propuesta para estos módulos, que de alguna manera anula o hace caso omiso de las anteriores investigaciones. Por supuesto también abandona la propuesta para realizar una construcción en aluminio, descartando por el momento llevar a la práctica su brevet $2.26 * 2.26 * 2.26$

\footnotetext{
${ }^{12}$ Según Bruno Chiambretto en su libro Le Cabanon, pag. 61, Le Corbusier inicia la reflexión sobre este nuevo proyecto en Julio de 1952 en el curso de un viaje, entre Cap Martin y Ajaccio, para supervisar la construcción del Cabanon. En el documento que se cita no es legible el lugar en el que está escrito, pero al existir coincidencia aproximada de fecha bien podría tratarse del mismo momento.
} 


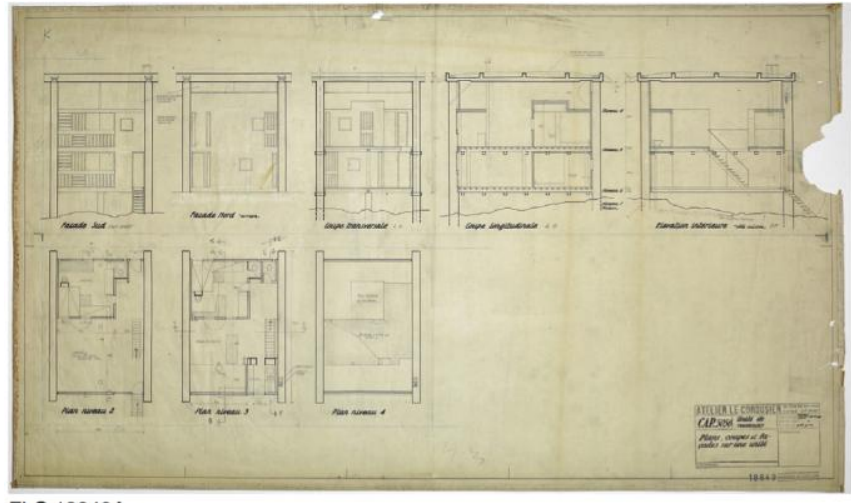

FLC 18849A

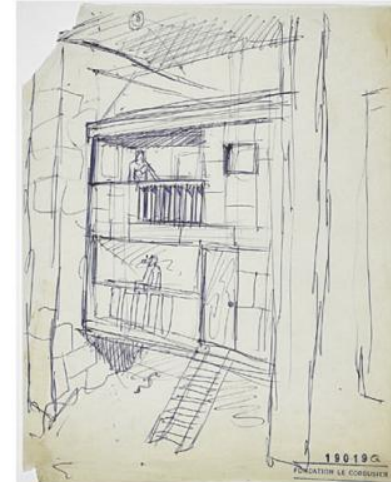

FLC 19019 Q

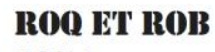

1954

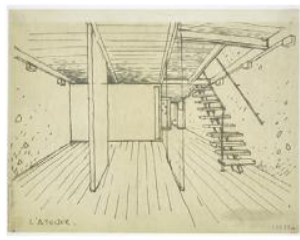

FLC 19036D

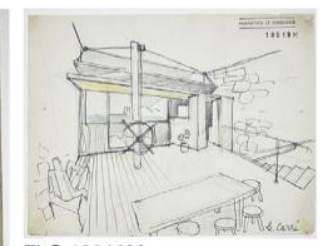

FLC 19019M

\section{A P}

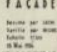
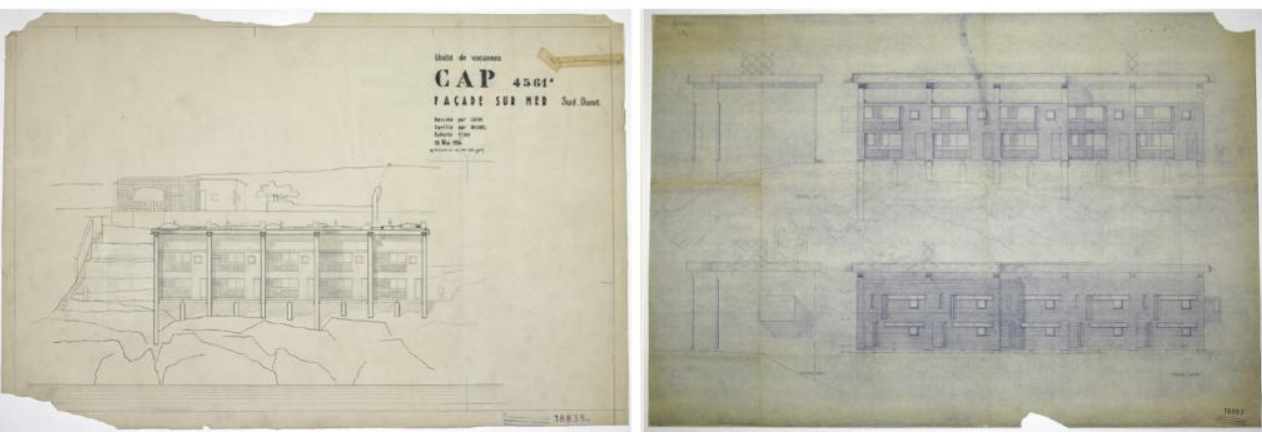

FLC18849A (Michel-Sachinidis, 19-05-1954), FLC 19019Q (NN, NF), FLC 19036D (NN, NF), FLC 19019 M (NN, NF), FLC 18835A (Sachinidis-Michel, 18-05-1954), FLC 18903 (NN, NF). Imágenes @FLC-ADAGP.

El proyecto para las Unités de Vacances se sitúa exactamente en el mismo lugar que estaba previsto Rob, en el terreno inmediatamente inferior a L’Étoile de Mer y el Cabanon y, al igual que las últimas versiones de aquel, está compuesto por cinco unidades, en este caso adosadas en grupos de dos y tres viviendas. Su construcción se prevé mediante muros de carga que no duplican la medianera y una estructura aparentemente de madera apoyada en ellos. La forma cómo se resuelve el programa también varía sustancialmente, ya que si bien las soluciones anteriores apuntaban a viviendas mas o menos convencionales resueltas en dúplex, en este caso realmente se proyecta un espacio para alojar a personas trabajando, y no a familias. El espacio está organizado mediante dos espacios de descanso confinados (3.66*3.66 metros) cada uno de ellos con 4 camas, una mesa y un aseo, una zona común de cocina y descanso y otro gran espacio quizás destinado al trabajo. Existe la posibilidad de disponer de cuatro camas adicionales sobre la cubierta del módulo superior y un espacio de aire que separa la cubierta del resto. La unidades básicas de descanso son una reproducción literal del Cabanon, cuya construcción terminó en Agosto de 1952 (FLC 19012, FLC 18827, FLC 18835, FLC 18836, FLC 18849A).

Si bien la construcción se levanta del suelo, ya no lo hace con una planta o dos, como en los anteriores tanteos, sino tan sólo con ocho escalones. El concepto constructivo se modifica por completo. Unos muros gruesos quizás de piedra (ver bocetos del espacio interior FLC 19019 P) y una cubierta pesada vegetal delimitan el todo. Se pueden apreciar a su vez varios dibujos en los que se hacen pruebas con respecto a la sintaxis entre muros y fachadas. Inicialmente se manifiestan los muros, retranqueándose el plano de fachada y disponiéndose unas gárgolas potentes coincidentes con cada muro (similares a las de Chandigarh) que enfatizan aún más la lectura de las unidades, mientras que en los dibujos de Kim de diciembre de 1953 (FLC 18854, FLC 18858, FLC 18903) se observa cómo se hace pasar la fachada por delante haciendo primar la visión del plano. Al parecer en las últimas versiones Le Corbusier planteaba recubrir las fachadas mediante una plancha de aluminio micro ondulada quizás 
similar a la inicialmente propuesta para el Cabanon. La composición tripartita cuerpo-aire-cubierta pesada recuerda a la estrategia empleada en los edificios lineales de Chandigarh.

Cómo se puede observar, a pesar de la intensidad de la búsqueda por ahora no parece haber conclusiones cerradas. Se podría afirmar que el maestro mantiene como premisas ciertas la permanencia de un ancho de crujía de 2,26 metros como base para la resolución del espacio interior de la vivienda, la voluntad de trabajar de una manera intensa en sus edificios el encuentro con el suelo y con el cielo, la necesidad de una respuesta al paisaje mediante la utilización de elementos que le sean propios y, finalmente, el deseo de aunar el uso de formas de construcción vinculadas a la tradición con las soluciones más innovadoras.

En febrero de 1955 Le Corbusier renunció definitivamente a la construcción de este proyecto bajo el pretexto de que el solar era potencialmente inundable, ya que una fuerte tormenta había causado destrozos recientemente. Es posible que la causa fuera parcialmente esa, pero no cabe despreciar el hecho de que tras seis años de trabajo, altruista, personal y obstinado, Le Corbusier no pareció encontrar una solución para establecer esa simbiosis entre paisaje y arquitectura que le satisficiera. Sólo su Cabanon, cuya principal característica es la ausencia de arquitectura, parecía convencerle.

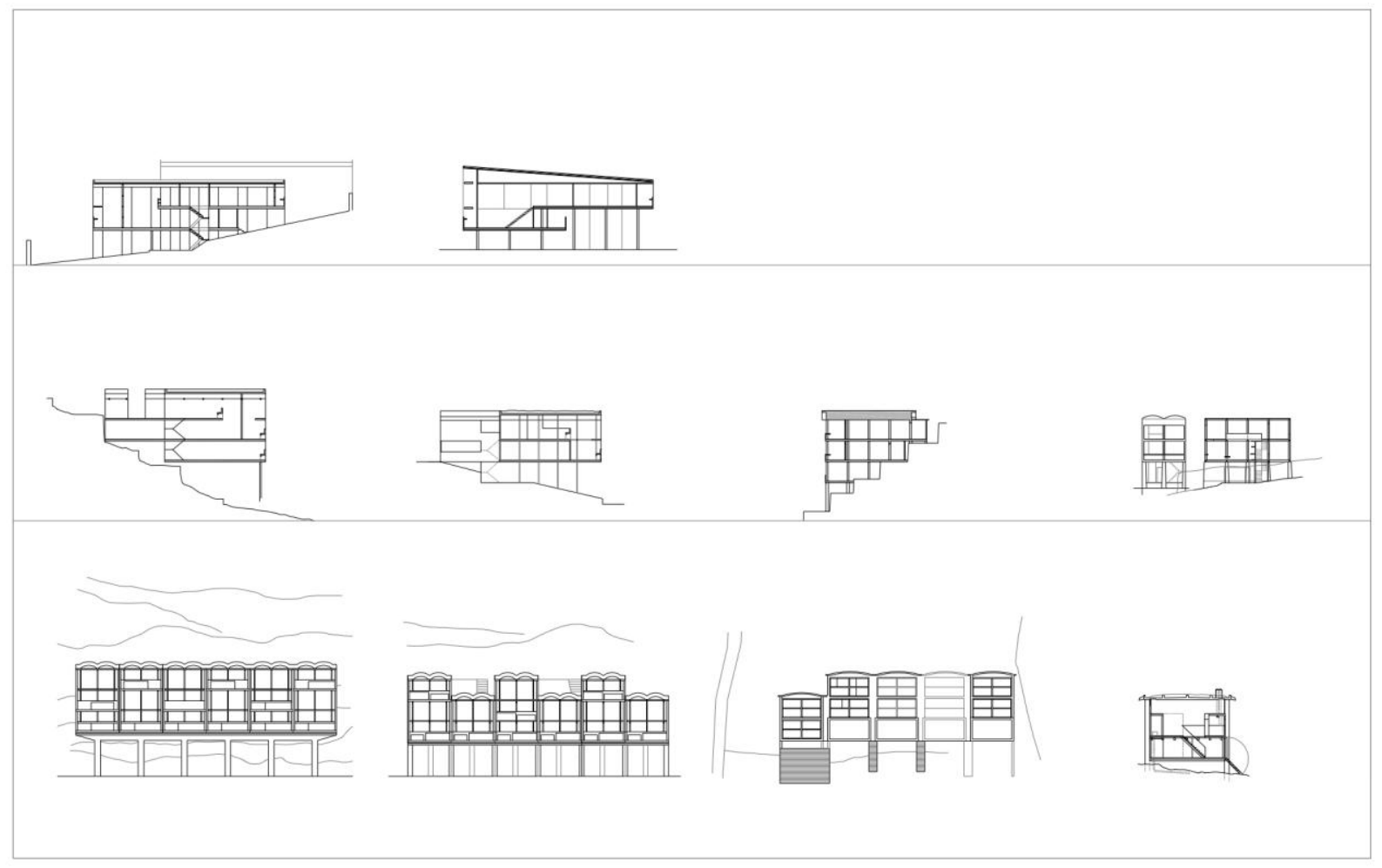

Esquemas comparativos de alzados y secciones para los proyectos de Roq et Rob y el Village de Pèlereniage de la SainteBaume ordenados cronológicamente. Redibujo C. Mejía- J. Deltell.

\section{Bibliografía}

Le Corbusier: Euvre Complète, Vol. 2. Zurich: Verlag für Architektur, Artemis, 1957. Octava edición 1991.

Le Corbusier: Euvre Complète, Vol. 5. Zurich:Verlag für Arkitektur, Artemis.

Le Corbusier: Plans. Paris: Codex Images International, Fondation Le Corbusier, 2005.

Chiambretto, Bruno: Le Corbusier à Cap Martin. Le Cabanon. Marseille: Éditions Paranthèses, 1987, 2006.

Petit, Jean: Le Corbusier Lui-même. Genève: Éditions Rousseau,1970. 